\title{
Ecoteologia: ciência da fé e espiritualidade
}

\author{
Ecoteology: science of faith and spirituality
}

AFONSO MURAD

\section{Resumo}

A consciência ecológica se tornou um diferencial na contemporaneidade. Cada vez mais pessoas e grupos descobrem que o ser humano é membro da Terra. A história do planeta se unifica. Nossa espécie é responsável para que a Casa Comum continue habitável para todos os seres, as gerações presentes e futuras. A teologia se lança sobre essa questão vital para o presente e o futuro da humanidade, não simplesmente como um tema da moral (ética ambiental) ou da dogmática (teologia da criação), e sim como uma nova perspectiva de pensar a fé, viver a espiritualidade e atuar no mundo. Esse artigo está dividido em duas partes. Na primeira, aborda o conceito de ecoteologia, relacionando a ecologia com a "ciência da fé". Compreende-se a ecologia como ciência, ética e paradigma. A seguir, mostra as características e o processo desenvolvido pela ecoteologia latino-americana. $\mathrm{Na}$ segunda parte apresenta alguns traços da espiritualidade ecológica que florescem com a ecoteologia: interdependência, encantamento, gratidão e louvor, ouvir a Palavra, profetismo, conversão e dinamismo do Espírito.

Palavras-chave: Ecoteologia. Ecoespiritualidade. Teologias libertadoras. Ecologia. Teologia.

\section{Abstract}

Ecologically conscious it has become a differential in contemporary times. Every time more people and groups discover that a human being is a member of Terra. The history of the planet is unified. We are responsible for ensuring that Common House continues to be habitable for all beings, present and future generations. Theology is launched on this vital question for the present and future of humanity, not simply as a subject of moral (environmental ethics) or of dogmatic (theology of creation), and also as a new perspective of thinking the faith, living the spirituality and acting in the world. This article is divided into two parts. First of all, it addresses the concept of ecotheology, relating ecology with "science of faith". Ecology is understood as science, ethics and

\footnotetext{
a Faculdade Jesuíta de Filosofia e Teologia (FAJE), Belo Horizonte, MG, Brasil. Doutor em Teologia, e-mail: murad4@hotmail.com
} 
paradigm. Next, it shows the characteristics and the process carried out in Latin American ecotheology. The second part presents some traces of ecological spirituality that flourish with ecotheology: interdependence, enchantment, gratitude and praise, word hearer, prophetism, conversation and dynamism of the Spirit.

Keyword: Ecotheology. Eco-spirituality. liberating theologies. Ecology. Theology.

\section{Introdução}

Ecologia é um tema recorrente na mídia, nas redes sociais e no cotidiano das pessoas. Não somente por causa dos problemas ambientais, como as mudanças climáticas, a destruição dos biomas e a perda da qualidade de vida nas cidades. A consciência ecológica se tornou um diferencial na contemporaneidade. Cada vez mais pessoas e grupos descobrem que o ser humano é filho da Terra, a história do planeta se faz uma e nossa espécie é responsável para que a Casa Comum continue habitável para todos os seres, nas gerações presentes e futuras. Somam-se atitudes pessoais, mobilização dos movimentos socioambientais em todo o mundo, iniciativas de empresas e governos em vista de uma sociedade sustentável. Desgraçadamente o poder público no Brasil, sobretudo em nível federal, atua na direção oposta, reduzindo as conquistas socioambientais, implementando uma política de aniquilamento dos biomas, com apoio tácito à mineração, ao garimpo e ao agronegócio insustentáveis, autorizando o uso de agrotóxicos ecocidas na agricultura, e perseguindo os povos indígenas, guardiões da floresta.

A teologia se lança sobre essa questão vital para o presente e o futuro da humanidade. Surge a ecoteologia. É evidente que ela se ocupa da ética ambiental (JUNGES, 2004) e da teologia da criação (SUSIN, 2003), mas vai bem além disso. Trata-se de uma nova perspectiva de pensar a fé, viver a espiritualidade e atuar no mundo. É uma corrente teológica contemporânea, legítima herdeira do Concílio Vaticano II, da Conferência de Medellín e da Teologia da Libertação, sob a ótica da consciência planetária.

O artigo está dividido em duas partes. Na primeira, aborda o conceito de ecoteologia, relacionando a ecologia à "hermenêutica da fé". Compreende a primeira como ciência, ética e paradigma. Mostra as características da ecoteologia latino-americana, sua relação de interdependência com outras 
correntes teológicas libertadoras e os avanços de sua reflexão. Na segunda parte, apresenta alguns traços da espiritualidade ecológica que florescem com a ecoteologia. O artigo seleciona, então, sete componentes peculiares da ecoespiritualidade, tecidos como uma unidade: interdependência, encantamento, gratidão e louvor, ouvinte da palavra, profetismo, conversão e dinamismo do Espírito.

\section{Ecoteologia: o que e para quê?}

Como o próprio termo enuncia, a ecoteologia articula a ciência ou hermenêutica da fé (teologia) com o saber, as práticas sustentáveis e o paradigma que constituem a ecologia. Vejamos como isso se realiza.

\section{Ecologia: do saber ao novo paradigma}

A ecologia estuda como se relacionam todos os "habitantes" do planeta, nossa Casa Comum: os seres abióticos (água, ar, solo, energia do sol), os seres bióticos (microorganismos, plantas e animais) e nós humanos, animais mamíferos singulares. Contribui para decifrar as causas da crise ecológica do planeta, e relaciona suas causas e consequências, pois é a ciência da interdependência. No primeiro sentido que se confere ao termo, a ecologia reúne uma série de ciências, teóricas e operacionais, que desvendam os complexos elementos da "teia da vida" e propõem soluções para a crise ecológica. Nesse amplo leque se colocam as ciências ambientais explícitas ${ }^{1}$, como a biologia, a climatologia, a geografia, os tratados sobre a água. Junto a elas, as ciências aplicadas com conotação ecológica, como o direito ambiental (VILAS BOAS; ROCHA, 2016), a eco-filosofia, a economia ambiental, a engenharia ambiental (BRAGA et al., 2005)², a geografia ambiental, os estudos

\footnotetext{
${ }^{1}$ Por exemplo: na grade curricular o Curso de Ciências Ambientais da UNIRIO há conjunto de disciplinas como: química orgânica, inorgânica e ambiental; toxologia ambiental; manejo e conservação do solo; geoprocessamento; planejamento, educação e gestão ambientais; biologia vegetal e animal; impacto ambiental, física geral e ambiental, ecologia humana, sociedade e meio ambiente, etc. Cf. http://www.unirio.br/ccbs/ibio/cursos/cienciasambientais/copy_of_ocurso/GradededisciplinasCA_antesreformacurricular.pdf.

2 Essa obra de Introdução à Engenharia ambiental compreende três partes com os respectivos capítulos: (I) Fundamentos: crise ambiental, leis da conservação da massa e da energia,
} 
de impacto ambiental, a gestão ambiental (ABDALLA DE MOURA, 2008), o ecodesign dos produtos e serviços, as pesquisas sobre ecoeficiência, a hidrologia, os estudos sobre poluição e recuperação do solo. E ainda podemos citar, entre outras tantas, a agroecologia (MACHADO; MACHADO FILHO, 2017) e a agricultura orgânica, simultaneamente teóricas e práticas. Afirma Leonardo Boff:

A ecologia é um saber de relações, interconexões, interdependências e intercâmbios de tudo com tudo em todos os pontos e em todos os momentos [...] Não é um saber de objetos de conhecimento, mas de relações entre os objetos de conhecimento. Um saber de saberes, entre si relacionados (BOFF, 2004, p. 17).

A crise ambiental e o desabrochar da consciência planetária põem em questão a visão sobre o humano e a forma como ele atua sobre a comunidade de vida da Terra (biosfera). Isso conduz a uma concepção ampla de ecologia, como um paradigma, ou modelo de compreensão. A ecologia questiona o antropocentrismo egóico e desequilibrado, que adveio com a ciência moderna e se consolidou com a tecnociência. Essa trouxe muitas soluções, mas criou vários problemas, a ponto de tornar os ecossistemas e a sociedade mais vulnerável (RIECHMANN, 2005). A esse antropocentrismo doentio se contrapõem o biocentrismo, o ecocetrismo e o antropocentrismo inclusivo. Eles consideram o valor de cada ser para a continuidade da vida no planeta, como também reconhecem, em diferentes graus, a singularidade da espécie humana. O último enfatiza a singularidade do ser humano, como ser de linguagem, que cria significados, faz história e atua sobre o ambiente, desenvolvendo assim processos civilizatórios. Os primeiros acentuam o valor intrínseco de cada ser que constitui a casa comum e sua relação de interdependência e cooperação nos ecossistemas.

Ao paradigma ecológico se liga o crescimento da consciência planetária, ou seja: o ser humano é fruto de um longo processo de evolução do cosmos, um filho(a) da Terra. A sobrevivência da espécie humana depende de caminhar para uma história convergente, para além das fronteiras e dos interesses de

ecossistemas, ciclos bioquímicos, dinâmica das populações, bases do desenvolvimento sustentável; (II) Poluição ambiental: energia e meio ambiente, o meio aquático, o meio terrestre, o meio atmosférico; (III) Desenvolvimento sustentável: conceitos básicos, economia e meio ambiente, aspectos legais e institucionais, avaliação de impactos ambientais, gestão ambiental (BRAGA et al., 2005). 
cada nação, e buscar uma "governança planetária", na qual os esforços e as alternativas somam e se entrelaçam. Estamos numa grande “Arca de Noé”. Ou sobreviveremos juntos, ou juntos pereceremos. A humanidade é responsável também pelas gerações futuras (intergeracional).

A consciência ecológica emergente traz uma grande oportunidade para a humanidade. Postula um estilo de vida mais simples, alegre, flexível, na qual a felicidade não se confunde com elevação de padrão de consumo. Esse se apresenta como o florescer humano, junto com os outros seres que fazem parte de nossa Casa Comum ${ }^{3}$. Nós, cristãos, os denominamos como “criaturas", pois elas existem por vontade amorosa e gratuita de Deus e se destinam à plenificação. E, ao seu conjunto, chamamos de "criação"4. Embora minoritários, pessoas e os grupos sociais, em diferente intensidade, estão buscando uma sintonia consigo mesmo, os outros, a natureza e o sagrado. Emergem, assim, estilos de vida alternativos e espiritualidades ecológicas, com elementos comuns em diversas tradições religiosas.

A ecologia, "saber de saberes" e novo paradigma inclui também uma ética. Ou seja: um conjunto de atitudes pessoais, ações coletivas, posturas institucionais, legislação, políticas públicas e tratados internacionais em defesa da Terra e pela inclusão social. Portanto, e ecologia comporta simultaneamente: ciência, paradigma e ética.

\section{Da teologia à ecoteologia}

A teologia surge nos primeiros séculos do cristianismo e se desenvolve no correr dos séculos. Ela visa responder à necessidade da comunidade eclesial de pensar sua fé e estimular seus membros a vivê-la na caridade e na

\footnotetext{
3 Cf. J. Riechmann (org). Como vivir? Acerca de la Vida Buena (2011). A imagem do "florescimento", a ser estimulada simultaneamente para a humanidade e todos os seres vivos, está presente nos princípios básicos ecologia profunda (Deep ecology), de A. Neiss (NAESS e SESSIONS, 1984). Segundo ele, a qualidade da vida humana "depende em parte do profundo prazer e satisfação que experimentamos ao compartilhar com outras formas de vida" (NEISS, 1973/2007, p .99).

${ }^{4}$ Criação é mais do que natureza, "porque tem a ver com um projeto do amor de Deus, onde cada criatura tem um valor e um significado [...] A natureza entende-se habitualmente como um sistema que se analisa, compreende e gere. [...] Criação (é) um dom que vem das mãos abertas do Pai de todos, como uma realidade iluminada pelo amor que nos chama a uma comunhão universal" (LS 76).
} 
esperança, estabelecer um diálogo com as culturas e povos, refutar acusações, assimilar e clarificar conceitos, criar imagens e analogias significativas. Em síntese, avançar no processo de interpretação da crença.

No âmbito católico, a teologia hegemônica nos últimos cinco séculos se ocupou fundamentalmente com a apologética, a dogmática e a moral. Diríamos, grosso modo: a primeira, consistia em mostrar a plausibilidade da revelação cristã e do catolicismo, em luta contra o ateísmo e a reforma protestante. A segunda, em explicar e replicar a doutrina cristã, condensada na Suma Teológica de Santo Tomás de Aquino. E por fim, a moral visava apresentar as listas de pecado e suas condicionantes, para subsidiar os confessores. Além disso, o seminarista, único personagem que tinha acesso à teologia, precisava estar munido de todas as normas referentes à administração dos sacramentos e a estrutura eclesiástica. Em lugar secundário se colocava a espiritualidade, que aparecia em forma narrativa e parenética nos relatos idealizados da vida dos santos, enquadrados num modelo estático (não tinham defeitos, desprezavam o corpo e "o mundo", e desde o início eram cheios de virtudes). A teologia apresentava de forma sistemática a espiritualidade cristã nos "tratados de ascética e mística".

No início do século $X X$ a teologia provou processos de renovação, a partir de várias iniciativas, sobretudo na Europa. Inspirada por grandes pesquisadores protestantes, emerge a teologia bíblica no âmbito católico. A teologia dogmática abre-se a novas categorias de pensamento. A ética cristã parte de Cristo e de seu apelo à conversão e ao seguimento. Novas correntes de espiritualidade, como também a releitura das clássicas, estimulam os fiéis a viver a espiritualidade no mundo, em suas relações cotidianas. Com o movimento ecumênico, cristãos de diversas Igrejas começam a derrubar muros e a construir pontes para viver juntos o Evangelho. Na Igreja católica, todo esse impulso renovador será assumido no Concílio Vaticano II. Assim, a teologia contemporânea se constitui como hermenêutica da Fé, com muitos interlocutores, a serviço da evangelização, da missão de anúncio e diálogo.

Mais do que uma área de estudo, a Bíblia volta a ser a base da toda Teologia. O setor da sistemática empreende um caminho renovador no seu método, traçado pelo decreto conciliar Optatam Totius: parte da Bíblia, percorre a patrística, enriquece-se com a Tradição legitimada nos Concílios e 
documentos Papais, sistematiza reflexão com conceitos antigos e novos, e descobre o sentido para o nosso tempo (OT 16). A moral cristã se amplia enormemente, libertando-se do rigorismo e da fixação no pecado. Enriquecese no diálogo com as ciências humanas. Incorpora novas disciplinas, como a bioética e a moral social. Embora ainda restringida no ensino acadêmico das faculdades de teologia, o diálogo ecumênico e inter-religioso passa a constituir um pressuposto consensual nos Congressos e Simpósios de teologia, especialmente os realizados com as Ciências da Religião.

Nessa trilha aberta pelo Vaticano II, surge a Teologia da Libertação, que não se inicia nas instituições de ensino superior, e sim nas práticas pastorais e no serviço efetivo aos pobres, em resposta aos grandes apelos da realidade humana. Ela é respaldada pela II Conferência do Episcopado Latino Americano, em Medellín (Colômbia), no ano de 1968.

A Teologia da Libertação (reflexão) e a Igreja dos pobres (prática) formam uma unidade indissolúvel. Os teólogos(as) aprendem da sabedoria e da resistência dos pobres no campo e na cidade. Desenvolvem uma forma didática de "falar das coisas de Deus", em diálogo. Agentes de pastoral (leigos/as, religiosos/as e padres) ajudam a organizar as comunidades e apresentam uma leitura libertadora da bíblia. Estimula-se a participação das lideranças nos movimentos populares em defesa dos camponeses, dos trabalhadores urbanos, das mulheres, dos povos indígenas e de todos os oprimidos. Consagra-se o protagonismo dos pobres e o método Ver - Julgar - Agir na pastoral. Criam-se gestos e palavras mais adequadas para traduzir esse estilo de ser cristã(o), nas celebrações comunitárias.

Filhas e companheiras da Teologia da Libertação, outras correntes teológicas surgem ou se desenvolvem de maneira própria no nosso continente, como a teologia feminista, a teologia índia, a teologia negra (afroamericana), a teologia gay ou queer, a ecoteologia e a teologia ecofeminista. Todas essas correntes são teologias contextuais. "Contextual" não significa somente "restrito a um determinado contexto" temporal, espacial ou cultural. Pois ao menos a ecoteologia e a teologia feminista estão presentes no mundo inteiro e dizem respeito a toda a humanidade, pois habitamos esse único planeta e as relações de gênero nos constituem, como homens ou mulheres, transgêneros ou cisgêneros. Tais teologias são 
contextuais porque consideram a dor e o crescente protagonismo dos pobres, das mulheres, dos povos originários e afrodescendentes e de outros sujeitos como parte irrenunciável de sua identidade e missão.

Elas são teologias críticas e construtivas. Críticas porque denunciam as práticas discriminatórias, os conceitos, os valores, as normas e os estereótipos de una sociedade excludente, patriarcal e racista. Apontam as consequências funestas da teologia quando essa reforça a "história única", na qual os(as) outros(as) são invisibilisados. De forma construtiva, elas se reapropriam da tradição cristã e a reconstroem criativamente a partir de um marco de interpretação libertador. Contribuem para o avanço da reflexão teológica, trazendo à luz elementos que foram esquecidos no seu longo trajeto de dois milênios. Tais teologias integram as diferentes experiências e linguagens sobre Deus, sem impor o discurso padronizado ou uma única experiência como normativos (RINCÓN ANDRADE, 2020, p.144).

\section{Singularidade da Ecoteologia}

O termo ecoteologia foi cunhado e difundido inicialmente por David G. Hallman, ex presidente do conselho mundial das Igrejas. Dentre suas obras, destaca-se Ecotheology: Voices from South and North, 1994. Mas vários teólogos e teólogas moldaram a ecoteologia antes que a palavra fosse formatada. Vale ressaltar a contribuição original de J. Moltmann em "Deus na Criação" (1989) e L. Boff, na clássica obra "Ecologia, grito da Terra, grito dos pobres" (2004). Os primeiros textos desses autores remontam à década de oitenta.

A ecoteologia latino-americana e caribenha é reflexão sobre a fé cristã ou a partir dela, que incorpora a consciência ecológica como elemento transversal. Ela não somente discursa sobre a ecologia com categorias religiosas (pois do contrário não seria teologia), mas principalmente intenta pensar a fé de forma ecológica. Isto é: de maneira interligada, articulando as diversas disciplinas e áreas de estudo que a constituem, continuando a proposta da opção pelos pobres de teologia da libertação e aprendendo das demais teologias libertadoras no nosso continente. Tal interdependência se mostra também na relação estreita do pensar com a espiritualidade e as 
práticas sustentáveis, em âmbito pessoal, comunitário e institucional. No dizer do Papa Francisco na Laudato Si':

Tudo está interligado. Por isso, exige-se uma preocupação pelo meio ambiente, unida ao amor sincero pelos seres humanos e a um compromisso constante com os problemas da sociedade (LS 91). Tudo está interligado, e isto convida-nos a maturar uma espiritualidade da solidariedade global que brota do mistério da Trindade (LS 240).

A ecoteologia é movida por algumas convicções, tais como: (a) A criação não é somente o palco onde acontece a história da salvação, mas participa ativamente dela; (b) Somos chamado por Deus a continuar a obra da criação e contribuir para leva-la à plenitude; (c) O clamor da Terra e o clamor dos pobres incita a uma conversão integral.

Resumidamente, a ecoteologia:

- reelabora a reflexão de fé em diálogo com as ciências ambientais, as práticas socioambientais e o paradigma ecológico;

- contribui no cuidado com o planeta, a sustentabilidade e o bem viver;

- desenvolve uma espiritualidade unificadora, celebrativa, alegre, esperançada, lúcida, conectada com o mundo humano e cósmico;

- articula a dimensão social da fé cristã e a consciência planetária, ampliando o horizonte da teologia da libertação;

- agrega elementos das teologias de gênero, afroamericana, indígena, decolonial, ecumênica e do pluralismo religioso, aprendendo delas e cooperando com elas;

- convoca todos(as) a desenvolver atitudes pessoais, ações coletivas, políticas institucionais e mudanças no processo de produção e distribuição dos bens, visando manter a terra habitável e promover a inclusão social dos pobres (MURAD, 2019).

Segundo Guridi (2018), a ecoteologia resulta do encontro da reflexão teológica com a crescente consciência ecológica. Essa nova consciência penetrou na teologia, mas também está presente em outras áreas do conhecimento e em práticas sociais. Permeia a educação, a economia, as artes, o planejamento urbano e os hábitos cotidianos. Como as outras teologias libertadoras, a ecoteologia realiza uma dupla tarefa hermenêutica: a crítica a partir da fé cristã, e a crítica da própria formulação que esta adquiriu na 
história. Isso configura um processo de revisão, recuperação, transformação e aprofundamento. A ecoteologia visa explicar "como e porque a sensibilidade ecológica é essencial para os crentes e uma parte nuclear de sua fé". Analisa a crise ecológica a partir de sua dimensão religiosa. Neste empenho, revisa a compreensão de Deus, de criação e do lugar do ser humano. Exerce simultaneamente a dupla função de crítica e reconstrução (GURIDI, 2018, p. 84-85, 87).

$\mathrm{Na}$ área da dogmática (ou sistemática) a ecoteologia naturalmente trata da teologia da criação, sob a ótica ecológica (SUSIN, 2000, 2003; MOLTMANN, 1989; JUNGES, 2001). Ela ampliou seu leque de reflexão, que foi respaldada e assumida na Laudato Si'. A ecoteologia penetra na antropologia teológica, refletindo sobre o lugar do ser humano na Terra5, e a dimensão ecológica da graça e do pecado. Na cristologia, ressalta a criação em Cristo e a ressurreição como início da Nova Criação ${ }^{6}$. Na escatologia, mostra como a tensão escatológica está presente na biosfera e traz à luz o tema do "Novo Céu e Nova Terra". Na reflexão sobre a Trindade, aponta que a biodiversidade e os laços de fraternidade humana se fundamentam na unidade e diferença em Deus ${ }^{7}$. Na teologia sacramental, especialmente a eucaristia, ressalta a elevação da matéria8.

$\mathrm{Na}$ área da Bíblia, a ecoteologia retoma com novo olhar o precioso tema da Aliança de Deus com seu povo, e suas implicações sociais e ambientais. Redescobre as dimensões socioambientais da mensagem dos profetas. Revisita os Salmos, nos quais há uma unidade admirável entre criação,

\footnotetext{
5 "A existência humana se baseia sobre três relações fundamentais intimamente ligadas: as relações com Deus, com o próximo e com a terra" (LS 66). "Cada comunidade pode tomar da bondade da terra aquilo de que necessita para a sua sobrevivência, mas tem também o dever de a proteger e garantir a continuidade da sua fertilidade para as gerações futuras" (LS 67).

6 "As criaturas deste mundo já não nos aparecem como uma realidade meramente natural, porque 0 Ressuscitado as envolve misteriosamente e guia para um destino de plenitude" (LS 100).

7 "Acreditar num Deus único que é comunhão trinitária, leva a pensar que toda a realidade contém em si mesma uma marca propriamente trinitária" (LS 239). "A pessoa humana cresce, amadurece e santifica-se tanto mais, quanto mais se relaciona, sai de si mesma para viver em comunhão com Deus, com os outros e com todas as criaturas. Assim assume na própria existência aquele dinamismo trinitário que Deus imprimiu nela desde a sua criação (LS 240).

8 "A criação encontra a sua maior elevação na Eucaristia. A graça, que tende a manifestar-se de modo sensível, atinge uma expressão maravilhosa quando o próprio Deus, feito homem, chega ao ponto de fazer-Se comer pela sua criatura. No apogeu do mistério da Encarnação, o Senhor quer chegar ao nosso íntimo através dum pedaço de matéria. Não o faz de cima, mas de dentro, para podermos encontrá-Lo a Ele no nosso próprio mundo" (LS 236).
} 
libertação histórica e salvação. Os Salmos também nos ensinam a louvar a Deus com todas as criaturas. A ecoteologia destaca ainda a relação entre Jesus de Nazaré, a causa do Reino de Deus e a cristologia cósmica.

Felizmente, há uma produção crescente de ecoteologia no Brasil, em outros países do nosso continente e no mundo. Entra-se no âmbito da patrística, mostrando como já nos primeiros séculos do cristianismo havia uma sensibilidade ecológica, compreendida à luz da fé em Jesus Cristo. Sobretudo nos padres da Igreja oriental (THEOKRITOFF, 2009). Relaciona-se o tempo litúrgico com o cuidado da criação (MÜSSIG, 2018). No âmbito da teologia do pluralismo religioso, a ecoteologia convida as religiões ao compromisso com a Casa Comum. Mostra que há nelas várias expressões de uma mística ecológica e apresenta tarefas comuns (MAÇANEIRO, 2011).

Vale ressaltar a contribuição da teologia ecofeminista, com uma produção significativa, que associa de forma vigorosa as questões de gênero com a ecologia. Ela denuncia as manifestações danosas do patriarcalismo na sociedade, na Igreja e na teologia. Apresenta como a opressão sobre os pobres e a mulheres e a exploração da Terra estão interligados. Considera as experiências das mulheres com um lugar hermenêutico da reflexão teológica e da prática pastoral. Reconhece que as mulheres são as principais cuidadoras da Terra. Articula narração, conceitos e poesia. Intenta inovar no método e na linguagem. Incorpora na ecoteologia a corporeidade humana. Considera a Terra como "corpo de Deus". Convida para novas relações de gênero, marcadas pela reciprocidade, pela igualdade nas diferenças. Ensaia um rosto feminino de Deus, em contraposição ao patriarcal (GEBARA, 1997; VÉLEZ, 2013).

A ecoteologia contribui em estudos interdisciplinares a respeito de temas socioambientais significativos, como a água (WOLFF, 2019), a segurança alimentar (PONTIFICIO CONSIGLIO DELLA GIUSTIZIA E DELLA PACE, 2015), a tecnociência (MURAD; REIS; ROCHA, 2019) e o enfrentamento das comunidades à mineração (BOSSI; MURAD, 2015). Insere na Bioética o imperativo de cuidar do planeta (PESSINI et al., 2015). Reflete sobre o modelo econômico vigente e critica sua visão de "desenvolvimento" (VIOLA; VIOLA, 2017). Propõe o "Bem Viver", uma nova forma de existir, produzir e consumir, que respeita o ambiente e promove relações saudáveis em vários níveis, 
retomando as tradições ancestrais dos povos andinos (ACOSTA; MARTíNEZ, 2009; FERNANDES DA COSTA; ROCHA SANTOS, 2019). Além disso, a ecoteologia aborda outros temas candentes, como o significado cultural e espiritual da alimentação (WIRZBA, 2014), e a "teologia da libertação animal" (SUSIN; ZAMPIERI, 2015).

Colaborando com os movimentos de cidadania e ecologia, a ecoteologia anima os cristãos a se engajarem nessas causas como algo fundamental de sua vocação no mundo e um caminho autêntico de santidade. "Viver a vocação de guardiões da obra de Deus não é algo de opcional nem um aspeto secundário da experiência cristã, mas parte essencial duma existência virtuosa" (LS 217).

Segundo Guridi, a ecoteologia redefine a noção de domínio e reinterpreta a tarefa de administrar o mundo como cultivar e guardar. Ela busca novas metáforas e conceitos para expressar a relação de Deus com as criaturas e o vínculo do ser humano com elas. Além disso, inspira práticas ecológicas amigáveis. A ecoteologia explicita paradigmas bíblicos e outras tradições teológicas que ofereçam uma compreensão da realidade distinta do dualismo grego e da estratificação hierárquica dos seres. Acentua o valor intrínseco de todas as criaturas, que tem sua origem em Deus. E propõe um conjunto de princípios éticos e critérios práticos para o discernimento de pessoas e de comunidades, em vista de novas formas de vida (GURIDI, 2018, p. 87).

Em publicações anteriores, apontamos como a ecoteologia propõe práticas pessoais e coletivas, visando a sustentabilidade e cuidado da Casa Comum. Concretamente, sugerimos várias ações comunitárias em paróquias (MURAD, 2016) e em escolas confessionais (MURAD, 2018). Agora, daremos um passo a mais. Explicitaremos algumas características da espiritualidade que cresce com a ecoteologia. 


\section{A "colcha de retalhos" da ecoespiritualidade9}

Podemos comparar a experiência de Deus em perspectiva ecológica às colchas de retalhos, tecidas por várias costureiras e artesãs. Cada parte se liga às outras, constituindo assim um belo conjunto. Essa colcha está sendo confeccionada nas nossas comunidades e grupos, que partilham e tecem uma ecoespiritualidade latino-americana. Processo ainda em curso, incompleto, com avanços e recuos. Propositalmente não se usa aqui o imperativo ("dever ser"), e sim o presente do indicativo, para indicar uma trilha que se faz. Como se trata de uma prática comunitária, da qual o autor participa muito mais como aprendiz do que como mestre, adota-se o pronome "nós". Selecionaram-se sete "retalhos" que estamos costurando e ligando: gratidão, encantamento, escuta da Palavra, profetismo, conversão, interdependência, no dinamismo do Espírito. Eles estão dispostos em ordem aleatória, pois, como numa colcha, pode-se começar por qualquer lado. Partimos de experiências reais, consideradas à luz da espiritualidade bíblica e da encíclica Laudato Si', do Papa Francisco.

(a) Interdependência. A cultura ocidental colonizadora fragmentou as pessoas e dividiu o conhecimento em partes que não se comunicam. Criou-se um abismo entre os interesses do indivíduo e da coletividade. Separou-se a razão da emoção, a linguagem científica da narração e da poesia. Nesse contexto, a religião foi reduzida às práticas devocionais, ao ritualismo litúrgico e à moral individualista. Perdeu seu sentido original de "religar" todas as coisas em Deus. A política e o poder econômico se uniram, configurando uma forma de produzir, consumir e descartar que destrói a Terra e marginaliza os pobres e os povos originários. A concentração da população nas cidades e especialmente nas suas periferias desconectou a população da natureza. Então, a espiritualidade foi privatizada. Transformou-se num instrumento de auto-ajuda, para oferecer paz interior, lidar com a depressão e garantir o sucesso. Aconteceu um desvio perigoso, pois se trocou o Deus de Jesus e do Reino, por "ídolos", criados na medida de seus adoradores.

\footnotetext{
${ }^{9}$ Este ítem sobre a ecoespiritualidade, inédito, será publicado no próximo ano na nova versão do Dicionário "Mysterium Liberationis", organizado por Ameríndia (Uruguai).
} 
Nesse cenário generalizado de fragmentação, a escoespiritualidade faz a diferença. Cremos que "tudo está interligado": as pessoas, as comunidades, as culturas, os povos e os ecossistemas que formam a biosfera. $O$ todo é mais do que a soma das partes. A solução para superar os desafios da complexa crise socioambiental "requer uma abordagem integral para combater a pobreza, devolver a dignidade aos excluídos e, simultaneamente, cuidar da natureza" (LS 139). Por isso, adotamos o Bem Viver como uma utopia possível e necessária. Promovemos a ecologia integral, que inclui aspectos ambientais, sociais, políticos (LS 138-142), culturais e da vida cotidiana. A busca de uma conexão com a Terra e com todos os humanos que se empenham por uma nova sociedade nos constitui por dentro, tanto na ação transformadora quanto na contemplação. Manifesta-se na palavra e no silêncio. Na solidariedade com os crucificados e na esperança da ressurreição.

Somos simultaneamente discípulos e missionários, aprendizes e anunciadores. Aprendemos lições de solidariedade e resistência no meio dos pobres. A natureza, na sua sabedoria, nos ensina a viver de maneira sustentável. Aprendemos uns dos outros, com as contribuições dos movimentos eco-feministas, dos transgêneros, dos povos indígenas e dos afrodescendentes, das novas gerações, das igrejas e das religiões. Acreditamos que a diversidade humana, como a biodiversidade, quando se põe em espírito de cooperação, enriquece e fortalece nossos laços. Aqui reside a oportundidade de conversão para acolher os diferentes, e exercitar o encantamento e a gratidão: "Como são numerosas tuas obras, ó Senhor. A todas fizestes com sabedoria. A Terra está cheia das tuas criaturas (SI 104,24).

(b) Encantamento. Para Jesus, somente quem desenvolve o coração de criança participa do Reino de Deus (Mt 18,1-4). Na ecoespiritualidade latinoamericana se cultiva a sensibilidade à beleza, na natureza, nas pessoas e nos processos históricos de libertação. A beleza dos ecossistemas e de cada criatura suscita em nós admiração e respeito. Como afirma o Papa Francisco, somos chamados a falar a língua da fraternidade e da beleza na nossa relação com o mundo. Se nos sentimos intimamente unidos a tudo o que existe, então brotam de modo espontâneo a sobriedade e o compromisso, como em Francisco de Assis (LS 11). A beleza faz parte do plano salvífico de Deus! E ela está ligada à prática do bem, a nível interpessoal e planetário. As outras 
criaturas e as pessoas, especialmente as marginalizadas e invisíveis na sociedade, não são coisas, pois carregam os sinais do Criador. "Sendo criados pelo mesmo Pai, estamos unidos por laços invisíveis e formamos uma espécie de família universal, uma comunhão sublime que nos impele a um respeito sagrado, amoroso e humilde" (LS 89).

Absorvido pelas dores do mundo, provocadas pela degradação do meio ambiente e das más condições de vida dos pobres, a pessoa corre o risco de se deixar levar pelo pessimismo. Então, trava uma luta constante para superar o desencanto e abraçar a esperança. Além disso, aprender a apreciar o que é belo, com lucidez e gratuidade, contribui para romper com a visão pragmática e dominadora do antropocentrismo moderno. Reconhecemo-nos assim como filhos e filhas da Terra (LS 2), irmãos e irmãs das outras criaturas. "Ressurge uma atitude de encantamento, reponta uma nova sacralidade e desponta um sentimento de intimidade e de gratidão [...] O universo dos seres e dos viventes nos enche de respeito, de veneração e de dignidade" (BOFF, 2004, p. 28). Gratidão e encantamento conduzem a alentar a alegria e o louvor: "Alegrai-vos sempre no Senhor" (Fil 4,4).

(c) Gratidão e louvor. A ecoespiritualidade é tecida com a atitude de gratidão aos humanos e à criação, e de louvor a Deus. Somos agradecidos pelos nossos ancestrais, sobretudo os mais próximos: os avós, o pai e a mãe. Ficamos felizes com as gerações atuais na família: filhos, sobrinhos e netos. Manifestamos gratidão às pessoas que nos formaram, àquelas com as quais constituímos comunidade e aos mártires que testemunham a paixão por Jesus e o Reino até a morte. Agradecemos aos amigos e amigas com os quais estabelecemos vínculos afetivos. Saboreamos as pequenas conquistas da luta pela justiça social e ambiental e somos gratos aos ativistas socioambientais. Tal atitude de reconhecimento estimula pessoas e grupos a continuarem no caminho do bem e a superar seus limites e imperfeições. Agradecemos à Terra, que nos dá as condições para existir e como mãe nos nutre com flores e frutos.

Tal espiritualidade, em relação ao Sagrado, é marcada pelo louvor e a Ação de Graças ao Deus da vida. Somos continuadores do povo da Bíblia, que entoava Salmos e Cânticos a Javé (SI 103, SI 149). Reconhecemos seu amor na Criação (SI 136,1-9) e na libertação das opressões históricas (SI 136,10-24; SI 146). Convocamos as criaturas para louvar e agradecer a Deus (SI 148; SI 150, 
Dn 3,57-88). Como Jesus, louvamos ao Pai porque revela seus segredos aos pequeninos (Mt 11,25). A exemplo de Maria, no Magnificat, cantamos os louvores a Deus e pedimos que ele derrube os poderosos de seus tronos e exalte os humilhados (LC 1,46-55).

(d) Ouvinte da Palavra na bíblia, na realidade e na Criação. As Igrejas da reforma pautarem seu caminho espiritual a partir da leitura da Bíblia. Os católicos acolheram tal princípio a partir do Concílio Vaticano II, sobretudo na constituição dogmática Dei Verbum, sobre a revelação divina. Nossa experiência de Deus está ancorada na leitura orante da Bíblia. A Palavra de Deus se torna companheira de cada dia, lâmpada para os pés na caminhada de fé e luz do nosso caminho (SI 119,105). Dela provamos e por ela somos provados (SI 34,8). Ela nos alimenta e fortalece (Dt 8,3). Sentimos sua doçura (Ez 3,3) e amargor, pois é preciso manter a profecia (Ap 10,8-10). Nela repousamos e ela não nos deixa descansar. Por isso, meditamos a Palavra de Deus e a colocamos no centro das nossas celebrações comunitárias.

No entanto, sua luz pode cegar as pessoas, quando se faz uma leitura fundamentalista da Bíblia. Por isso, a sensibilidade para acolher a Palavra escrita exige ouvir os apelos de Deus na realidade, e discernir os "Sinais dos Tempos". Essa expressão, que remonta ao evangelho (Mt 16,3), foi retomada pelo Papa João XXIII e pela Constituição Pastoral Lumen Gentium, do Concílio Vaticano II, sobre a Igreja no mundo de hoje. Segundo o concílio, a Igreja deve perscrutar os sinais dos tempos e interpretá-los à luz do Evangelho, para responder de maneira atualizada às interrogações sobre o significado da vida presente e futura. É necessário conhecer e entender o mundo no qual vivemos, suas esperanças, suas aspirações e seus dramas (GS 4).

A essas duas dimensões de escuta das interpelações de Deus, na Bíblia e na realidade, a ecoteologia acrescenta uma terceira: acolher o "evangelho da Criação", título do capítulo II da Laudato Si. Há uma "palavra sem palavras" em cada criatura e nos ecossistemas (SI 19,1-4). A natureza é um livro esplêndido onde Deus nos fala e transmite algo da sua beleza e bondade (LS 12). Como todas as criaturas estão interligadas, professamos com carinho o valor de cada uma delas, e que todos nós, criaturas, precisamos uns dos outros (LS 42). Então a espiritualidade ecológica implica em sermos ouvintes atentos 
da Palavra, que se manifesta de maneiras diferentes e complementares na Criação, na Bíblia e na realidade pessoal, social e planetária.

(e) Profetismo. Nas escrituras judaicas são os profetas aqueles que melhor tematizam a espiritualidade transformadora, que relaciona a palavra de Deus com a realidade pessoal e social. Por isso, há uma fusão de horizontes do profetismo bíblico com a missão profética da comunidade eclesial na contemporaneidade. Isaías, Jeremias, Amós e Oséias são personagens próximas a nós. A partir de suas palavras e gestos reconhecem-se os profetas e as profetizas de hoje. Eles(as) anunciam com coragem a Boa Nova de Jesus, denunciam as injustiças sociais e ambientais e nos convidam a abraçar a esperança. Dos profetas de ontem e hoje assimilamos a paixão por Deus, que nos comove e instiga (Jer 7,20). Semelhantes a Isaías e os primeiros discípulos de Jesus, ouvimos a voz do Senhor: “Quem enviarei, quem irá por nós?” e respondemos: “Aqui estou, envia-me” (Is 6,8; Mt 4,19). Como os profetas da bíblia, mantemos a indignação! Denunciamos uma religião vazia e de aparência (Is 1,10-16). Ajudamos a desmascarar os mecanismos políticos, econômicos e ideológicos que mantém a pobreza e destroem nossos biomas. Não podemos deixar de falar daquilo que experimentamos, vimos e ouvimos (Am 7,14-15, At $4,20)$ ! O anúncio profético nos coloca em situações de conflito, incompreensão e perseguições, na Igreja e na sociedade (Jer 20,8-10; Jo 15,20).

Aprendemos, desde a Conferência de Medellín, que a fé tem uma dimensão social irrenunciável (Medellín, 1968, documentos: “Justiça”, "Paz" e “Pobreza na Igreja”). Por empatia, experimentamos como nossa a dor do planeta e dos pobres. Provamos a força dos empreendimentos solidários e dos movimentos socioambientais, como também sua fraqueza diante do imenso poder das corporações que comandam o mercado global. O profetismo exige a atuação política, ambiental e social, mas não se reduz a ela. Tem sua raiz na experiência mística de ser tocado pelo Deus da Vida, que nos ama e nos convoca. Sentimos a necessidade de constantemente escutar a Palavra e deixá-la ressoar no coração; exercitar o encantamento e a gratidão, a súplica e a ação de Graças. Nos tempos atuais, a profecia exige a sabedoria, que a completa. Cultivamos a sabedoria, o conhecimento com sabor, a descoberta da presença de Deus no cotidiano e nas coisas pequenas da existência. Um dos temas caros aos profeta é a conversão. 
(f) Conversão pessoal, social e ecológica: os cristãos vivem numa constante luta interior. Fomos criados em Cristo, contemplados desde o ínicio pela Graça de Deus (Ef 1,4-5). E não somente nós. Toda a Criação é manifestação da bondade de Deus e participa do seu plano de salvação (Ef $1,10)$. As culturas, etnias e povos encarnam, de diferentes modos, valores que apontam para o Bem Viver. De outro lado, o Mal e a iniquidade estão presentes, em distintos graus, em cada ser humano, nas suas relações interpessoais, nas culturas, e na forma como se organizam a economia, a política e a distribuição dos bens. O pecado nos fragmenta, dificultando que integremos nossos desejos e pulsões. Cria obstáculos para a cooperação e estimula a competição e o egoísmo, cada um para si. O ser humano e a sociedade apresentam, simultaneamente e em diferentes graus, luzes e sombras, bondade e maldade, sensibilidade e indiferença.

Jesus começa sua missão convocando: "O Reino de Deus está chegando! Convertam-se e creiam no evangelho" (Mc 1,15). Nossa experiência de Deus está marcada pelo empenho de conversão, de perceber o que nos desvia do caminho de Jesus, pedir perdão e retomar a trilha. Conversão implica tanto a mudança do mal para o bem quanto o salto do bom para o melhor, de uma visão estreita para uma mais ampla. "Nunca maltratamos e ferimos a nossa casa comum como nos últimos dois séculos. Mas somos chamados a tornar-nos os instrumentos de Deus Pai para que o nosso planeta seja o que Ele sonhou ao criá-lo e corresponda ao seu projeto de paz, beleza e plenitude" (LS 53).

Nessa jornada, combatemos ao mesmo tempo os pecados pessoais e os estruturais. O documento final Sínodo para a Amazônia convoca a um movimento "da escuta à conversão integral", que se traduz em novos caminhos de conversão pastoral, cultural, ecológica e sinodal. "A escuta do grito da terra e do grito dos pobres e dos povos da Amazônia com os quais caminhamos nos chama a uma verdadeira conversão integral, com uma vida simples e sóbria, toda alimentada por uma espiritualidade mística no estilo de São Francisco de Assis, exemplo de conversão integral vivida com alegria e louvor cristão" (SÍNODO, 2019, n.17).

(g) No dinamismo do Espírito: A Ecoteologia e a espiritualidade que com ela nasce, redescobrem o Espírito Santo. Força feminina de Deus, a ruah 
dança sobre as águas no início da criação (Gn 1,2). Presente na ciranda da vida do nosso planeta, sustenta os ciclos de matéria e energia e impulsiona a evolução do cosmos e da humanidade, até a sua consumação. Promove a colaboração e interdependência de todas as criaturas na nossa Casa Comum. “Vínculo infinito de amor, o Espírito está intimamente presente no coração do universo, animando e suscitando novos caminhos" (LS 238). Fogo amoroso abrasador, vento impetuoso que desacomoda e traz o novo (At 2,1-2), brisa que nos reconforta, defensor dos pobres e fracos, que possibilita a emergência do novo e do surpreendente (BOFF, 2013, p.10). O Espírito unge os profetas (Is 61,1-2) e Jesus de Nazaré (Lc 4,18-19) para evangelizar e restaurar o mundo ferido. Ele/ela nos ajuda a recordar e atualizar a mensagem de Jesus (Jo 14,26). O Espírito Santo nos remete ao Deus Pai materno, princípio de toda vida. Faznos retornar, com um coração renovado, à pessoa e à mensagem de Jesus.

Na colcha de retalhos da existência humana no planeta há tecidos rotos, que precisam ser trocados, como nossas avós faziam. Um desses, está no gemido de toda a criação, qual mulher em situação de parto, ao ver a degradação da casa comum. O sofrimento também é constitutivo da espiritualidade ecológica, que não deixa de gemer, junto com a criação, na esperança da libertação e da transmutação do nosso corpo (Rm 8,19-23).

A relacionalidade humana e da natureza tem sua raiz na Trindade. "Tudo está interligado, e isto convida-nos a maturar uma espiritualidade da solidariedade global que brota do mistério da Trindade" (LS 240). Assim, no Espírito, cultivamos uma espiritualidade trinitária, relacional, amorosa, e de justiça recriadora. E nele clamamos: "Envia teu Espírito Senhor, e renova a face da Terra" (SI 104,30).

\section{Conclusão aberta}

A ecologia latino-americana e caribenha faz parte da Boa Nova do Evangelho para os tempos atuais. Em um contexto de "distopia" e perda de sonhos, ela traz consigo sinais de esperança. É possível e necessária uma nova postura do ser humano em relação à comunidade de vida do planeta, que à luz da fé chamamos de "criação". Não mais de saqueador e dominador. E sim, de irmão e administrador que protege e cultiva. Em vez de consumismo, 
sobriedade feliz. No lugar do pragmatismo e da busca de sucesso individual, laços de fraternidade e interdependência. A ecoteologia, unindo a reflexão (teoria) ao estímulo de práticas sustentáveis, enraizadas na espiritualidade, constitui uma resposta a anseios profundos do ser humano. Abre-se como alternativa para cultivar um novo estilo de vida, alegre, simples, equilibrado, em comunhão com todos os seres que habitam nossa Casa Comum. Contribui para a realização da Ecologia Integral, proposta por Francisco na Laudato Si'. Quem dera ela se enraíze e seja difundida nos cursos de teologia, nos espaços pastorais e na vida cotidiana dos cristãos.

\section{Referências}

ABDALLA DE MOURA, L. A. Qualidade e gestão ambiental. São Paulo: Juarez de Oliveira, 2008.

ACOSTA, A.; MARTíNEZ, E. (orgs.). El Buen Vivir. Una vía para el desarollo. Quito: AbyaYala, 2009.

BOFF, L. Ecologia: Grito da Terra, Grito dos pobres. Rio de Janeiro: Sextante, 2004 (Nova edição revista e ampliada: Vozes, 2015).

BOSSI, E; MURAD, A. (orgs.). Igreja e mineração. Em defesa da vida e dos territórios. Brasília: CNBB, 2015.

BRAGA,B. et al. Introdução à Engenharia ambiental. São Paulo: Pearson, 2005, 2ed.

COMPÊNDIO DO VATICANO II. Constituições, Decretos, Declarações. Organizado por Frei Frederico Vier. Petrópolis: Vozes, 2000.

CONCLUSÕES da Conferência de Medellín, 1968: (trinta anos depois, Medellín é ainda atual?) São Paulo: Paulinas, 2010.

FERNANDES DA COSTA, R.; ROCHA SANTOS, F (orgs.). A mística do Bem Viver. Belo Horizonte: Senso, 2019.

GEBARA, I. Teologia ecofeminista. Ensaio para repensar o conhecimento e a religião. Olho d’água, 1997.

GURIDI, R. Ecoteología: hacia um nuevo estilo de vida. Santiago: Ed. Universidad Alberto Hurtado, 2018.

JUNGES, J. R. Ética ambiental. São Leopoldo: Unisinos, 2004.

JUNGES, R. Ecologia e criação. São Paulo: Loyola, 2001. 
MAÇANEIRO, M. Religiões e ecologia. Cosmovisão, valores, tarefa. São Paulo: Paulinas, 2011.

MACHADO, M.; MACHADO FILHO. Dialética da agroecologia. Contribuição para um mundo com alimentos sem veneno. São Paulo: Expressão Popular, 2017.

MOLTMANN, J. Dios en la creación. Doctrina ecológica de la creación. Sígueme: Salamanca, 1987.

MURAD, A. Da ecologia à ecoteologia. Uma visão panorâmica. Revista Fronteiras, Fortaleza, v. 2, n. 1, p. 65-97, 2019.

MURAD, A. Gestão, exercício do poder e da sustentabilidade: uma reflexão multidisciplinar para gestores de escolas confessionais. In: DASSOLER, O. B. (org.). Escolas Católicas. Uma gestão em rede para a longevidade da obra. Curitiba: Positivo, 2018. p.127-164.

MURAD, A. Laudato Si - Pistas pastorais para conhecer e colocar em prática. In: MURAD, A.; TAVARES, S. T. (orgs). Cuidar da Casa Comum. Chaves de leitura teológicas e pastorais da Laudato Si'. São Paulo: Paulinas, 2016. p.218-239.

MURAD, A; REIS, E.V.B; ROCHA, M. (orgs.). Tecnologia e ecologia: múltiplos olhares. Rio de Janeiro: Lumen luris, 2019.

MÜSSIG, D. Hacia um cristianismo ecológico. Aportes bíblicos y litúrgicos para el cuidado de la creacíon. Cochabamba: Itinerários, 2018.

NAESS, A. "Los movimientos de la ecología superficial y la ecología profunda: un resumen” (original: 1973). Revista Ambiente y Desarrollo, Santiago de Chile, v. 23, n. 1, p. 98-101, 2007.

NAESS. A; SESSIONS, G. Basic Principles of Deep ecology. The Anarchist Library. 1984/2011. Disponível em: theanarchistlibrary.org. Acesso em: 1 nov. 2020

FRANCISCO (LS). Encíclica Laudato Si sobre o cuidado da Casa Comum. São Paulo: Paulinas, 2015.

PESSINI, L. et al. Bioética em tempos de globalização. São Paulo: Loyola, 2015, p. 105-126.

PONTEFICIO CONSIGLIO DELLA GIUSTIZIA E DELLA PACE. Terra e Cibo. Vaticano: Ed. Vaticana, 2015.

REIS, E. V. B; ROCHA, M. (orgs). Filosofia, direito e meio ambiente: aproximações e fundamentos para uma nova ética ambiental. Belo Horizonte: 3i editora, 2016.

RIECHMANN, J. (org.). Como vivir? Acerca de la Vida Buena. Madrid: Catarata, 2011

RIECHMANN, J. Un mundo vulnerable. Ensayos sobre Ecología, ética y tecnociencia. Madrid: De la Catarata, 2005, 2 ed. 
RINCÓN ANDRADE, M. La teología ecofeminista y la ecología integral. Un diálogo sobre el futuro de nuestra casa común. Tese (Doctorado em Teología). Pontificia Universidad Javeriana, Bogotá, 2020.

SUSIN, L. C. (org.). Mysterium Creationis: um olhar interdisciplinar para o universo. São Paulo: Paulinas, 1999.

SUSIN, L. C. A criação de Deus. São Paulo: Paulinas, 2003.

SUSIN, L. C. A criação de Deus. São Paulo: Paulinas, 2003.

SUSIN, L. C; ZAMPIERI; G. A vida dos outros. Ética e Teologia da Libertação animal. São Paulo: Paulinas, 2015.

THEOKRITOFF, E. Abitare la Terra. Uma visione Cristiana dell'ecologia. Magnano: Qiqajon, 2009.

UNIRIO. Grade curricular do Curso de Ciências Ambientais. 2020. Disponível em: http://www.unirio.br/ccbs/ibio/cursos/cienciasambientais/copy_of_ocurso/GradededisciplinasCA_antesreformacurricular.pdf. Acesso em: 1 nov. 2020

VÉLEZ, C. Teología feminista latinoamericana de la liberación: balance y futuro. Horizonte, Belo Horizonte, v. 11, n. 32, p. 1801-1812, out./dez. 2013.

VIOLA, A. N. B; VIOLA, F. I. (orgs). Repensar el desarollo. Aportes en torno a Laudato Si'. Buenos Aires: GRAMA, 2017.

VILAS BOAS; E.; ROCHA, M. Filosofia, Direito e Meio Ambiente: aproximações e fundamentos para uma nova ética ambiental. Belo Horizonte: 3i Editora, 2016.

WIRZBA, N. Alimento e fé. Uma teologia da alimentação. São Paulo: Loyola, 2014. WOLFF, E. (org.). Águas para a vida! Apelo aos povos e seus credos. São Paulo: Recriar, 2019. 